\title{
Enhanced battery model including temperature effects
}

\author{
Bogdan Roşca ${ }^{1}$, Steven Wilkins ${ }^{2}$ \\ ${ }^{1}$ Bogdan Roşca (corresponding author), TNO Science and Industry - Automotive, \\ P.O. Box 756, 5700 AT Helmond, The Netherlands, Bogdan.Rosca@TNO.nl \\ ${ }^{2}$ Steven Wilkins, TNO Science and Industry - Automotive, \\ P.O.Box 756, 5700 AT Helmond, The Netherlands, Steven.Wilkins@TNO.nl
}

\begin{abstract}
Within electric and hybrid vehicles, batteries are used to provide/buffer the energy required for driving. However, battery performance varies throughout the temperature range specific to automotive applications, and as such, models that describe this behaviour are required.

This paper presents a dynamic battery model describing the battery voltage based on current and temperature. A model identification method is presented and validation tests are performed. The results show that when temperature influences are included in the models, a significant increase in performance can be achieved. Modelling errors lower that $5 \%$ are achieved for validation tests conducted at $-10^{\circ} \mathrm{C}, 0^{\circ} \mathrm{C}$ and $10^{\circ} \mathrm{C}$, whereas the models that do not consider temperature show errors up to $10 \%$.
\end{abstract}

Keywords: lithium battery, battery model, battery SoH

\section{Introduction}

With the scarceness of fossil fuels and the stringent emission regulations that are being put in place, hybrid (HEVs) and electric vehicles (EVs) are being developed at an increased pace. EVs rely on batteries for providing the energy required for driving, while HEVs use batteries for temporary energy storage during driving with the goal of optimizing fuel efficiency and/or increasing performance.

The high production cost of batteries, together with their inherent characteristics (the nonmeasurable nature of important parameters) motivated a great deal of research on battery modelling and state estimation ([1] [2] [3] [4] [5] [6] [7] [8]).

Temperature plays an important role in the behaviour of the battery, both on longer and shorter time scales. It is recognized that temperature affects the present battery performance [1]. Its effects on a longer scale, relevant to battery ageing phenomena, have also been reported in literature ([9] [10] [11] [12] [13]).

For range prediction, an important information is the amount of energy the battery can provide/receive. Energy management strategies re- quire an accurate description of the power losses occurring within the battery, so that the most cost effective energy source (in the case of hybrid vehicles) is used at every moment. In the case of regenerative braking, the charge acceptance of the battery is extremely relevant, as it directly affects the required split between standard (mechanical) and regenerative braking. Different charging strategies (faster or slower home charging, on route charging, etc.) can be developed considering the trade-off between user requirements (having enough energy in the battery at a specified moment in time) and cost efficiency (balancing between the variable grid prices and considering battery ageing behaviour).

For all these applications, it is important to have a good mathematical description of how the battery operates. In this work, the electrical battery model presented in [8] is extended to include temperature effects. A model identification procedure is presented and validation tests are performed.

This paper is built up as follows. Section 2 describes the battery model developed in this work. The model identification procedure is presented in Section 3, while Section 4 describes the experimental results and the validation phase. In 


$$
\begin{aligned}
& \left(\begin{array}{c}
S o C_{k} \\
V_{1, k} \\
V_{2, k}
\end{array}\right)=\left(\begin{array}{ccc}
1 & 0 & 0 \\
0 & 1-\frac{\Delta t}{R_{1} C_{1}} & 0 \\
0 & 0 & 1-\frac{\Delta t}{R_{2} C_{2}}
\end{array}\right)\left(\begin{array}{c}
S o C_{k-1} \\
V_{1, k-1} \\
V_{2, k-1}
\end{array}\right)+\left(\begin{array}{c}
\frac{\Delta t}{C_{n}} \\
\frac{\Delta t}{C_{1}} \\
\frac{\Delta t}{C_{2}}
\end{array}\right) I_{b a t, k-1} \\
& V_{b a t, k}=V_{o c}\left(S o C_{k}, T_{k}\right)+V_{1, k}+V_{2, k}+R_{0}\left(S o C_{k}, T_{k}\right) I_{b a t, k} \\
& V_{o c}(S o C, T)=\kappa_{0}+\alpha_{0} T+\frac{\kappa_{1}}{S o C}+\alpha_{1} T S o C+\kappa_{2} S o C+\alpha_{2} T \ln (S o C)+ \\
& \underbrace{\kappa_{3} \ln (S o C)+\alpha_{3} T \ln (1-S o C)+\kappa_{4} \ln (1-S o C) \quad[\mathrm{V}]}_{f_{1}(S o C, T)} \\
& R_{0}(S o C, T)=\underbrace{\left\{\begin{array}{cc}
\left(\gamma_{0}^{+}+\cdots+\gamma_{c O}^{+} S o C^{c O}\right)\left(\nu_{0}^{+}+\cdots+\nu_{c 1}^{+} T^{c 1}\right), & \text { if } I_{b a t, k} \geq 0 \\
\left(\gamma_{0}^{-}+\cdots+\gamma_{d O}^{-} S o C^{d O}\right)\left(\nu_{0}^{-}+\cdots+\nu_{d 1}^{-} T^{d 1}\right), & \text { if } I_{b a t, k}<0
\end{array}\right.}_{f_{2}(\text { SoC }, T)}
\end{aligned}
$$

Section 5, concluding remarks are given.

\section{Battery model considering tem- perature effects}

The existing battery battery model was developed in [8] and is shown in Figure 1. It consists of an ideal voltage source, $V_{o c}[\mathrm{~V}]$, which is State-of-Charge (SoC) dependent, an internal resistance $R_{0}[\Omega]$, SoC dependent and different for charging and discharging, and two RC blocks, used to mimic the dynamic behavior of the battery. For more in depth information about battery dynamic behavior, the interested reader is referred to [1].

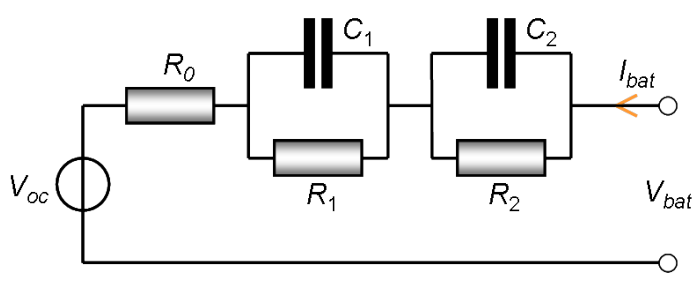

Figure 1: Dynamic battery model

A hybrid approach is followed to introduce temperature dependence in the existing battery model. The procedure consists of a mixture between physical and phenomenological battery modelling. The physical considerations originate from electrochemical battery modelling (see [14]) whereas electric circuit components were used to emulate the observed battery behavior. The resulting model has the same outline as the one shown in Figure 1. It is written in state space form in equation (1), with battery current $I_{b a t}$
[A] as input and battery voltage $V_{b a t}[\mathrm{~V}]$ as output. The states of the model are the SoC and the voltages of the two RC blocks. The state-space model is written in discrete time. The sampling time is $\Delta t$ [s] and the battery capacity is $C_{n}$ [As]. The temperature effects are included in the open circuit voltage $\left(V_{o c}\right)$ and internal resistance $\left(R_{0}\right)$ respectively.

Equation (2) shows the dependence of the open circuit voltage on battery State-of-Charge and temperature, with $\kappa_{0: 4}$ and $\alpha_{0: 3}$ unknown parameters.

The dependence on temperature and $\mathrm{SoC}$ of the internal resistance is described by equation (3), where $\gamma$ and $\nu$ are unknown parameters, different for charging and discharging. The order of the SoC polynomial is $c O$ (charging) and $d O$ (discharging) while the temperature polynomial is of order $c 1$ (charging) and $d 1$ (discharging).

\section{Model identification procedure}

For the identification procedure presented in this chapter it is assumed that the battery voltage, current and temperature are measured with a sample frequency of at least $1 \mathrm{~Hz}$.

Figure 2 presents a discharge cycle used for the model characterisation. It originates from a $\mathrm{LiFePO}_{4}$ battery module with a nominal voltage of $26.5 \mathrm{~V}$ and a nominal capacity of $160 \mathrm{Ah}$.

The design of the test cycle (consisting of current pulses of different amplitudes), allows identification of the internal resistance from the instantaneous change in battery voltage as a result of a stepwise change of the current, as it can be seen in Figure 3, at time value 100s.

The internal resistance can then be computed as:

$$
R_{0}=\frac{\Delta V}{I_{\text {step }}} \quad[\Omega]
$$




$$
H_{R}=\left[\begin{array}{cccccccccc}
1 & \ldots & S o C_{1}^{c 0} & T_{1} & \ldots & T_{1} S o C_{1}^{c O} & \ldots & T_{1}^{c 1} & \ldots & S o C_{1}^{c O} T_{1}^{c 1} \\
\vdots & \vdots & \vdots & \vdots & \vdots & \vdots & \vdots & \vdots & \vdots & \vdots \\
1 & \ldots & S o C_{n}^{c 0} & T_{n} & \ldots & T_{n} S o C_{1}^{c O} & \ldots & T_{n}^{c 1} & \ldots & S o C_{n}^{c O} T_{n}^{c 1}
\end{array}\right]
$$
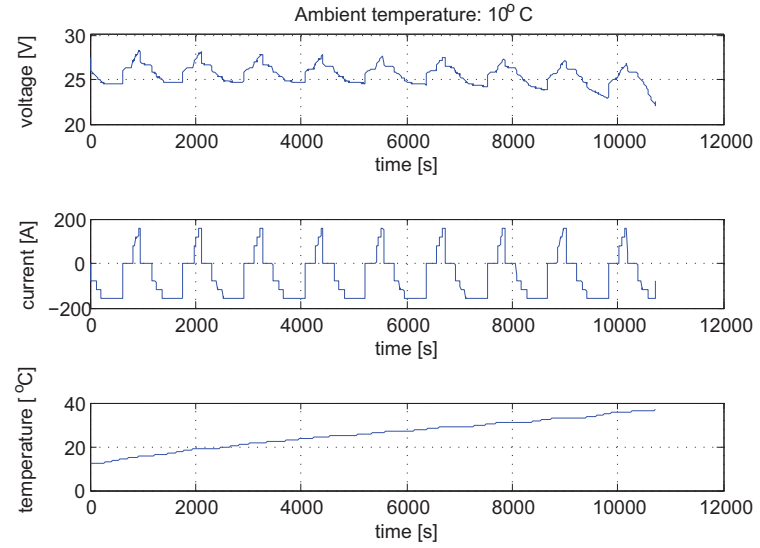

Figure 2: Discharge test with $10^{\circ} \mathrm{C}$ ambient temperature
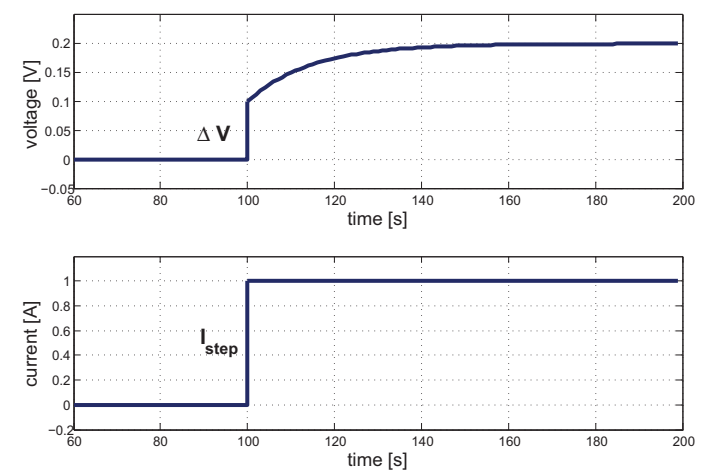

Figure 3: Step response

where $\Delta V[\mathrm{~V}]$ is the instantaneous step in voltage and $I_{\text {step }}[\mathrm{A}]$ is the amplitude of the current step.

After multiple values of the internal resistance have been computed, the unknown parameters of equation (3) can be identified using a least squares approach.

For each identified $R_{0}$, the corresponding values of $T$ and $S o C$ were determined. The $S o C$ is computed by integrating current, starting from a known initial value, according to the state update equation of the state space model presented in equation (1). Knowing these values, we can write equation (3) for each measurement point.

$$
\underbrace{\left[\begin{array}{c}
R_{0,1} \\
\vdots \\
R_{0, n}
\end{array}\right]}_{R_{0}}=\underbrace{\left[\begin{array}{c}
f_{2}\left(S o C_{1}, T_{1}\right) \\
\vdots \\
f_{2}\left(S o C_{n}, T_{n}\right)
\end{array}\right]}_{H_{R} \Phi_{R}}
$$

The equation above is valid for both the charging and the discharging internal resistance. For simplicity, only the charging case will be treated here. The discharging internal resistance can be determined analogously.

In equation (6), $R_{0}$ is the vector of the internal resistances whereas $H_{R}$ depends only on temperature and SoC (see below) and $\Phi_{R}$ is the vector of the unknown parameters that are to be identified. The unknown parameters can be determined as the least squares solution of equation (6):

$$
\Phi_{R}=\left(H_{R}^{T} H_{R}\right)^{-1} H_{R}^{T} R_{0}
$$

Please note that the elements of $\Phi_{R}$ are not exactly $\gamma$ and $\nu$ from (3), but the results of the multiplications of the coefficients of the $T$ and $S o C$ polynomials of the same equation.

After the parameters describing the internal resistance have been identified, the voltage drop over $R_{0}$ is computed.

$$
V_{R 0}=\underbrace{H_{R} \times \Phi_{R}}_{R_{0}(S o C, T)} \times I_{b a t}
$$

In equation (8), $R_{0}(S o C, T)$ represents the identified internal resistance (the functional dependence shown in (3) with the identified parameters).

If equation (2) is written for each measurement point, the following is obtained:

$$
\underbrace{\left[\begin{array}{c}
V_{o c, 1} \\
\vdots \\
V_{o c, n}
\end{array}\right]}_{V_{o c}}=\underbrace{\left[\begin{array}{c}
f_{1}\left(S o C_{1}, T_{1}\right) \\
\vdots \\
f_{1}\left(S o C_{n}, T_{n}\right)
\end{array}\right]}_{H_{V} \Phi_{V}}
$$

$H_{V}$ can be computed based on $T$ and $S o C$ :

The unknown parameters are then given by the least squares solution:

$$
\Phi_{V}=\left(H_{V}^{T} H_{V}\right)^{-1} H_{V}^{T} V_{o c}
$$

At this point, the internal voltage cannot be independently determined. However, the sum between $V_{o c}$ and the voltage drops over the two RC blocks can be computed. 


$$
H_{V}=\left[\begin{array}{ccccccccc}
1 & T_{1} & \frac{1}{S o C_{1}} & T_{1} S o C_{1} & S o C_{1} & T_{1} \ln \left(S o C_{1}\right) & \ln \left(S o C_{1}\right) & T_{1} \ln \left(1-\operatorname{SoC} C_{1}\right) & \ln \left(1-S o C_{1}\right) \\
\vdots & \vdots & \vdots & \vdots & \vdots & \vdots & \vdots & \vdots & \vdots \\
1 & T_{n} & \frac{1}{S o C_{n}} & T_{n} S o C_{n} & S_{0} C_{n} & T_{n} \ln \left(S o C_{n}\right) & \ln \left(S o C_{n}\right) & T_{n} \ln \left(1-\operatorname{SoC} C_{n}\right) & \ln \left(1-\operatorname{SoC} C_{n}\right)
\end{array}\right]
$$

$$
V_{b a t}-V_{R 0}=\underbrace{V_{o c}+V_{r c 1}+V_{r c 2}}_{V_{d y n}}
$$

Looking back at equation (1), it can be seen that the internal voltage is linearly independent of the voltage drops over the two RC blocks. This allows the use of $V_{d y n}$ instead of $V_{o c}$ for determining $\Phi_{V}$ :

$$
\Phi_{V}=\left(H_{V}^{T} H_{V}\right)^{-1} H_{V}^{T} V_{d y n}
$$

The internal voltage is then:

$$
V_{o c}=H_{V} \times \Phi_{V}
$$

The voltage of the two RC blocks can be computed as:

$$
V_{r c 1}+V_{r c 2}=V_{d y n}-V_{o c}
$$

At this point, the parameters describing the RC blocks can be identified using the method presented in [4].

\section{Experiments and validation}

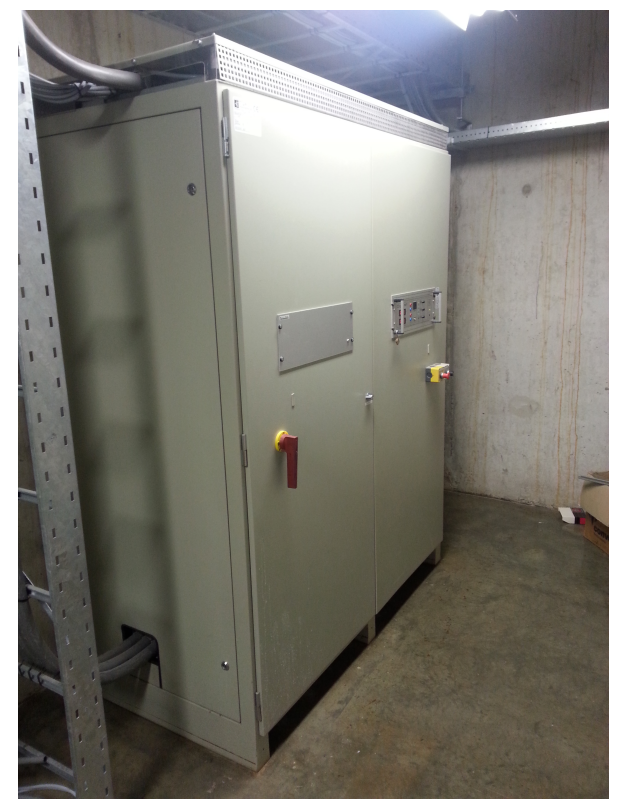

Figure 4: Digatron BS-400 battery test system

To validate the proposed method, experimental tests were conducted on a battery pack produced by Mastervolt (type MLi 24/160). The tests consisted on applying a sequence of current pulses of different amplitudes, both for charging and discharging. This was done under different ambient temperatures, ranging from $-18^{\circ} \mathrm{C}$ to $40^{\circ} \mathrm{C}$.

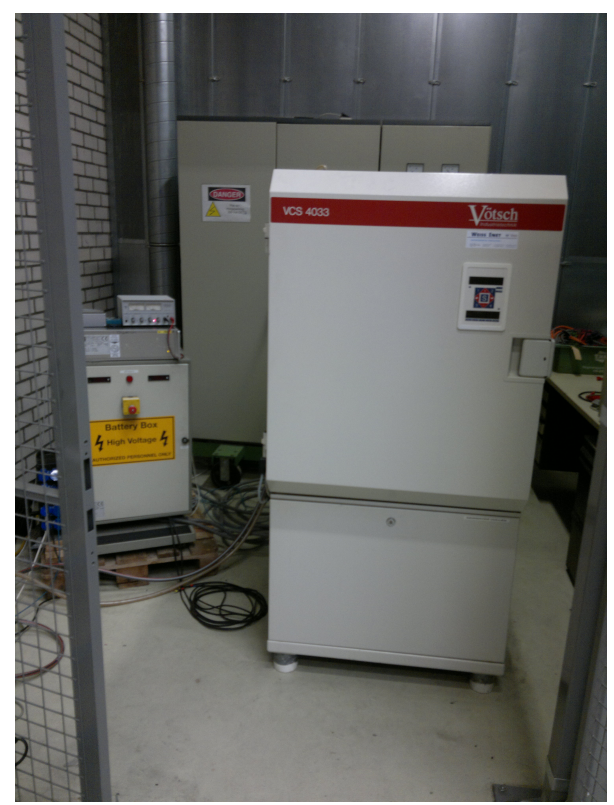

(a) Climate chamber

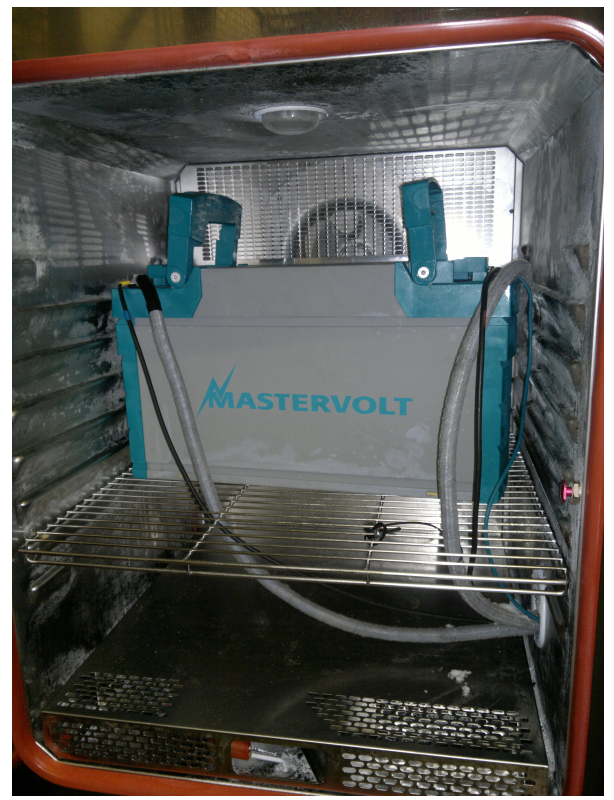

(b) Battery pack

Figure 5: Test setup

The charging and discharging of the battery 
were performed with the Digatron BS-400 (programmable high voltage source and sink).

The different ambient temperatures were obtained by placing the Mastervolt battery (Figure $5 \mathrm{~b}$ ) inside a climate cabinet (Votsch VCS4033, see Figure 5a) which can accurately regulate ambient temperature and humidity.

Each test was started with a full battery, charged according to the CCCV (constant current constant voltage) procedure. To achieve repeatability, each charging event took place at an ambient temperature of $10^{\circ} \mathrm{C}$ and a battery temperature (at the start of the charge profile) of $35^{\circ} \mathrm{C}$.

The tests were conducted at ambient temperatures of $-18^{\circ} \mathrm{C},-10^{\circ} \mathrm{C}, 0^{\circ} \mathrm{C}, 10^{\circ} \mathrm{C}, 25^{\circ} \mathrm{C}$ and $40^{\circ} \mathrm{C}$. The battery temperature equaled the ambient temperature at the start of the tests. Starting from these measurements, the battery internal resistance $R_{0}$ as a function of temperature and SoC has been identified, as presented in Figure 7.

The red stars in the figure represent the values of $R_{0}$ identified directly from the step responses, on which the least-squares identification procedure is based. Significant temperature influences on the internal resistance can be seen.

Figure 6 presents the dependence of the internal voltage on temperature and SoC, which is obtained as a result of the model parameters identification procedure. The data points used for the identification routine can be seen in black.

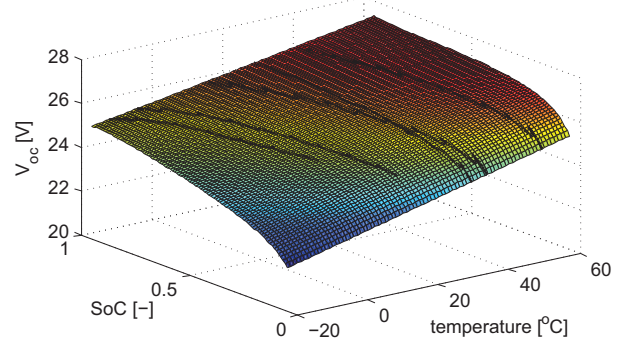

Figure 6: Identified internal voltage, as a function of temperature and $\mathrm{SoC}$

Figure 8 shows a comparison between a model not including temperature influences (model presented in [8], identified using data measured at $25^{\circ} \mathrm{C}$ ambient temperature) and the model developed in this work. For simplicity, the model developed in [8] will be referred to as model 1, while the one proposed in this work, including temperature effects, as model 2. Three of the tests are analyzed, with data collected at $-10^{\circ} \mathrm{C}$, $0^{\circ} \mathrm{C}$ and $10^{\circ} \mathrm{C}$ ambient temperature. In each test case, for model 2, the data collected in the other 5 tests is used for model identification. The RC parameters were identified using the $25^{\circ} \mathrm{C}$ test, at SoC value of 0.5 . For simplicity, these parameters were used for both models.

It can be seen that, as the temperature decreases, the accuracy gain of the model developed in this work increases. This is mostly the result of ac- counting for the increase in the internal resistance due to lower temperature. In Figure 8a ambient temperature of $-10^{\circ} \mathrm{C}$, the difference between the voltage prediction of the two models during current pulses (described in Figure 2) is significantly bigger than in Figure 8c - ambient temperature of $10^{\circ} \mathrm{C}$.

Figure 9 looks at the voltage prediction errors, expressed as percentile values - see equation (16). In all cases, it can be seen that including temperature effects in the model brings an important increase in performance.

$$
\text { error }=\frac{V_{\text {model }}-V_{\text {measured }}}{V_{\text {nominal }}} \times 100 \quad[\%],
$$

where $V_{\text {nominal }}$ is the nominal battery voltage, specified by the manufacturer.

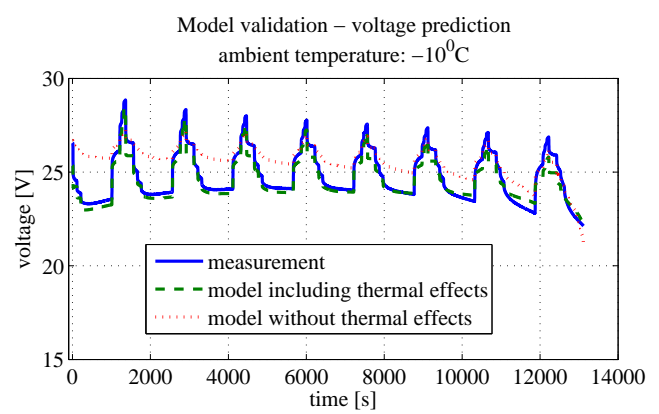

(a) test 1

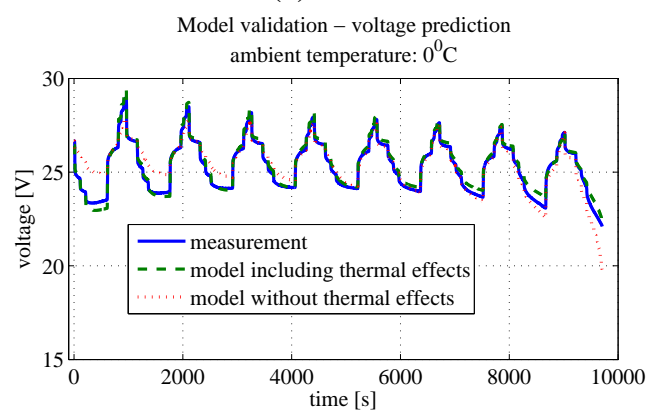

(b) test 2

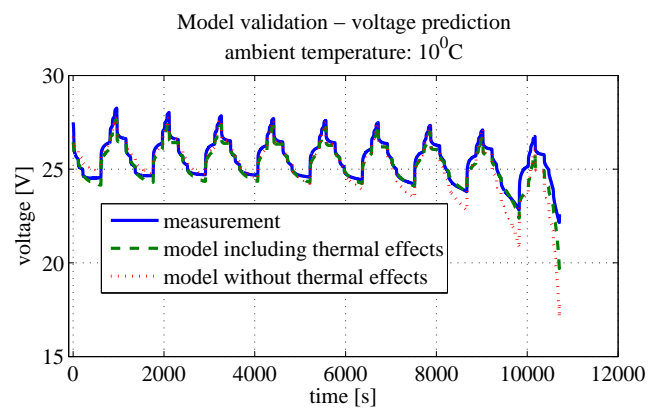

(c) test 3

Figure 8: Voltage prediction at different temperatures

A closer look at the error characteristics shown in Figure 9 reveals some interesting aspects. At the beginning of the three cycles, the model which does not take into account temperature effects is conservative in estimating the voltage drops. 
CHARGING

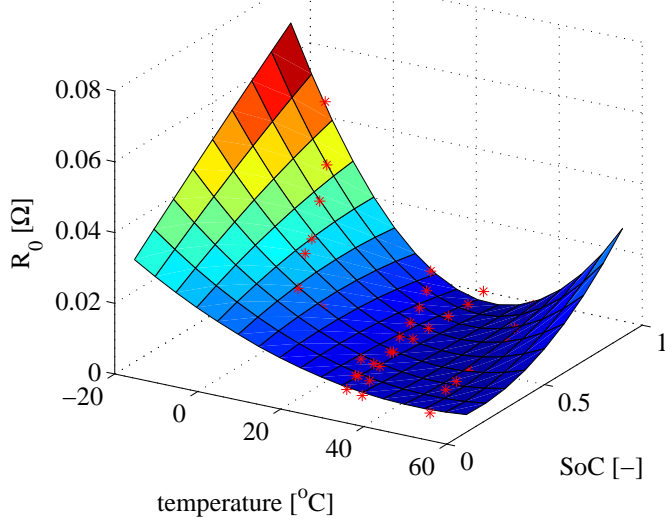

DISCHARGING

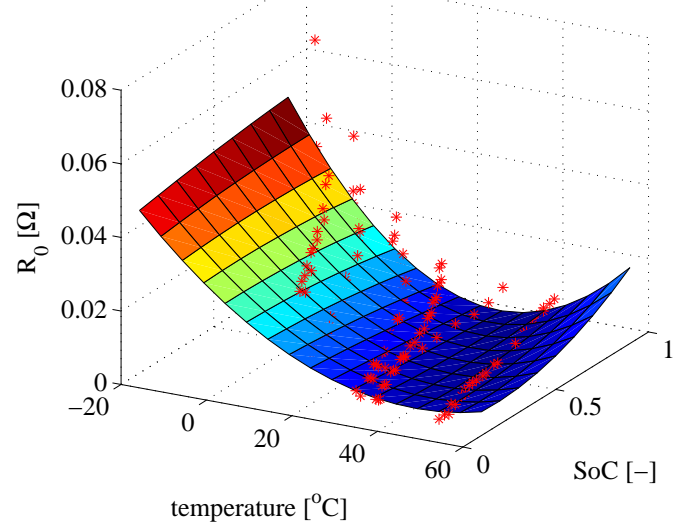

Figure 7: Identified internal resistance, as a function of temperature and SoC, for charging and discharging

This is due to the impedance increase with decreasing temperature. As the battery is discharged, a decrease is visible in the relative errors obtained by model 1 . They start with high positive values at high SoC and decrease to low negative values for low SoC, not unlike the behaviour of the temperature during the tests ( Figure 10 shows the battery temperature as a function of SoC for the $10^{\circ} \mathrm{C}$ test). This suggests that the errors of model 1 partly originate from not accounting for temperature.

For all three tests, Figure 9 shows that the errors of model 2 are more constant over the entire SoC range. The error shapes seem to suggest a temperature influence on the $\mathrm{RC}$ model parameters, which can be addressed as future work.

Overall, the figures show that a significant increase in voltage prediction accuracy can be achieved when temperature effects are taken into account by the model. Further accuracy increases are possible when temperature influences are considered for more model parameters.

\section{Conclusions}

In this work, a battery model including thermal effects has been developed, together with a model identification procedure. Coupled, the two show encouraging results, with voltage modelling errors smaller than $5 \%$, compared to $10 \%$, if temperature effects are not included.

Experimental tests suggest a strong temperature influence on the impedance characteristic of the battery. Information found in [14], where an electrochemical modelling approach is followed, backs up this assumption. The present work captures a part of this behaviour in the $R_{0}$ dependence on temperature. A direction to further improve the model accuracy is an investigation on the temperature and SoC effects on the $\mathrm{RC}$ parameters.

Nonetheless, in its present form, the temperature inclusion in the model offers a significant increase in voltage prediction performance. Sev- eral applications will take full advance of this increase of performance. On one side, range prediction algorithms for electric vehicles become more accurate over a wider range of environmental temperatures, while beneficial influences are also expected in model based energy management strategies for hybrid vehicles. Furthermore, smart regenerative braking algorithms gain a better insight into the charge acceptance of the battery over a wide temperature range.

For a number of applications (vehicle sizing and configuration analysis tools, controls development tools, battery second life applications, total cost of ownership (TCO) models), the ability to capture the ageing characteristics of automotive traction batteries is essential. The detrimental effect of higher temperatures on battery ageing is widely documented ([9] [10] [11] [12] [13]).

Impedance losses are an important source of the heat generated in the battery [15]. As the battery impedance changes with battery temperature, so does then its heat generation capability.

A coupled electro-thermal cell model has been developed to describe this behaviour. This model is then used as a building block in an electrothermal battery pack model. The aim is to correctly describe the relevant stress factors (temperature, but also Depth-of-Discharge or current rates) for battery aging during the vehicle usage of the battery. The derived stress factors are then fed into battery aging models to asses the degradation of the battery pack.

\section{Acknowledgments}

Part of this work has been funded by the ERANET+ ABattReLife European project.

The authors would like to acknowledge the contribution of Mastervolt International BV, which supplied the battery used in this work. 


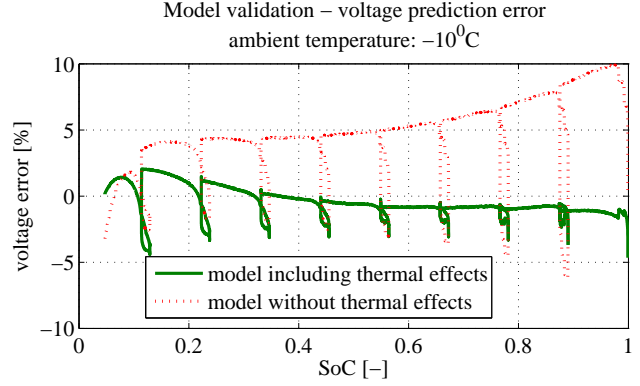

(a) test 1

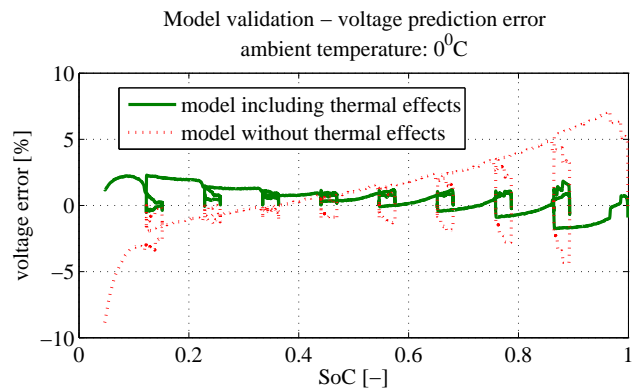

(b) test 2

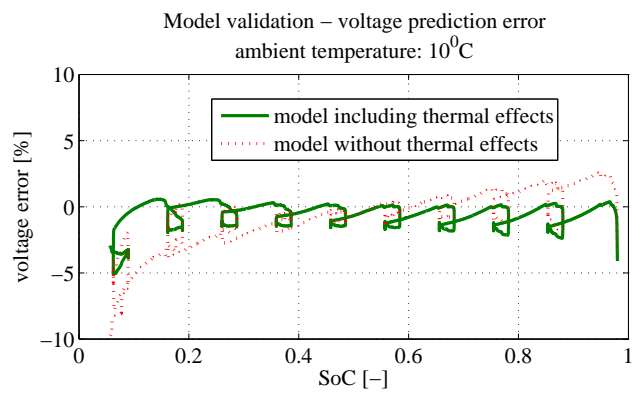

(c) test 3

Figure 9: Voltage prediction errors at different temperatures

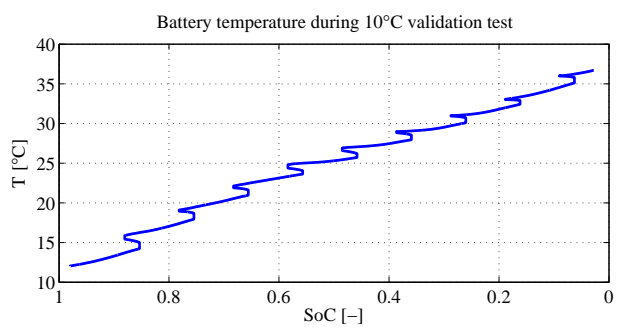

Figure 10: Battery temperature as a function of SoC during the $10^{\circ} \mathrm{C}$ test

\section{References}

[1] A. Jossen, "Fundamentals of battery dynamics," J. of Power Sources, vol. 154(2), pp. 530-538, March 2006.

[2] J. Kessels, B. Rosca, H. Bergveld, and P. van den Bosch, "On-line Battery Identification for Electric Driving Range Pre- diction," in Vehicle Power and Propulsion Conference, (Chicago, U.S.A.), September 2011.

[3] H. Zhang and M.-Y. Chow, "Comprehensive Dynamic Battery Modeling for PHEV applications," in Proc. of the IEEE Power and Energy Society General Meeting, (Minneapolis, MN), 2010.

[4] S. Jiang, "A Parameter Identification Method for a Battery Equivalent Circuit Model," in Proc. of the SAE 2011 World Congress \& Exhibition, no. 2011-01-1367, 2011.

[5] D. D. Domenico, A. Stefanopoulou, and G. Fiengo, "Lithium-Ion Battery State of Charge and Critical Surface Charge Estimation Using an Electrochemical ModelBased Extended Kalman Filter,' J. of Dynamic Systems, Measurement and Control, vol. 132, November 2010.

[6] G. L. Plett, "Extended Kalman filtering for battery management systems of LiPBbased HEV battery packs," J. of Power Sources, vol. 134, pp. 252-292, 2004.

[7] J. Wang, B. Cao, Q. Chen, and F. Wang, "Combined state of charge estimator for electric vehicle battery pack," Control Engineering Practice, vol. 15, pp. 1569-1576, 2007.

[8] B. Rosca, J. Kessels, H. Bergveld, and P. van den Bosch, "On-line Parameter, State-of-Charge and Aging Estimation of Li-ion Batteries," in Proc. of the IEEE Trasactions on Vehicular Technology, (Seoul, South Korea), October 2012.

[9] M. Ecker, J. B. Gerschler, J. Vogel, S. Kabitz, F. Hust, and P. Dechent, "Development of a lifetime prediction model for lithiumion batteries based on extended accelerated aging test data," J. of Power Sources, vol. 215, pp. 248-257, May 2012.

[10] I. Bloom, B. Cole, J. Sohn, S. Jones, E. Polzin, V. Battaglia, G. Henriksen, C. Motloch, R. Richardson, T. Unkelhaeuser, D. Ingersoll, and H. Case, "An accelerated calendar and cycle life study of li-ion cells," J. of Power Sources, vol. 101, pp. 228-247, February 2001.

[11] I. Bloom, S. Jones, E. Polzin, V. Battaglia, G. Henriksen, C. G. Motloch, R. B. Wright, R. Jungst, H. Case, and D. Doughty, "Mechanisms of impedance rise in highpower, lithium-ion cells," J. of Power Sources, vol. 111, pp. 152-159, May 2002.

[12] A. Eddahech, O. Briat, E. Woirgard, and J. Vinassa, "Remaining useful life prediction of lithium batteries in calendar ageing for automotive applications," Microelectronics Reliability, vol. 52, pp. 24382442, July 2012. 
[13] M. Broussely, S. Herreyre, P. Biensan, P. Kasztejna, K. Nechev, and R. Staniewicz, "Aging mechanism in li ion cells and calendar life predictions," Microelectronics Reliability, vol. 52, pp. 2438-2442, July 2012.

[14] V. Pop, H. Bergveld, J. O. het Veld, P. Regtien, D. Danilov, and P. Notten, "Modeling battery behavior for accurate state-ofcharge indication," J. Electrochem. Soc., vol. 153(11), pp. A2013-A2022, November 2006.

[15] S. A. Hallaj, H. Maleki, J. Hong, and J. Selman, "Thermal modeling and design considerations of lithium-ion batteries," J. of Power Sources, vol. 83, pp. 1-8, January 1999.

\section{Authors}

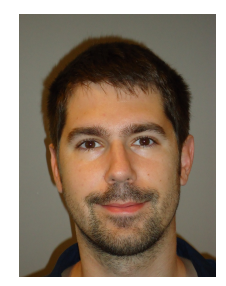

Bogdan Roşca obtained his M.Sc. degree in Automotive Technology from the Eindhoven Technical University, in 2011. He is currently a research engineer at TNO, the Dutch Organization of Applied Research, in the Powertrains Department. His activities include battery modelling and state estimation, powertrain modelling and control and driver behavior characterization. $\mathrm{He}$ is currently involved in the ABattReLife European project, studying the ageing behaviour of Li-ion batteries in automotive applications.

Steven Wilkins has a background in hybrid and electric powertrain modelling and simulation, originally based at Imperial College London where he completed his doctorate and post-doctoral studies, and retains a position as a visiting academic. $\mathrm{He}$ is now based in the Netherlands as a re-

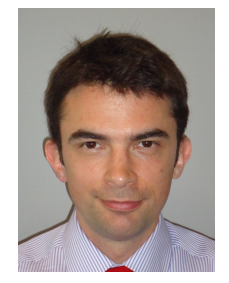
search scientist within TNO, the Dutch Organization of Applied Research. He is a member of the Powertrains department, is an active member of EARPA, and is involved in the ABattReLife European project amongst others. 